\title{
The Educational, Health, and Economic Impacts of COVID-19 Among Haitians in the USA: Time for Systemic Change
}

\author{
Judith L. Semé ${ }^{1}$ Balkys L. Bivins ${ }^{2}$. Candice A. Sternberg ${ }^{3}$. Juanita D. Barnett ${ }^{4}$ - Thamousca Junis-Florian ${ }^{5}$. \\ Guerda Nicolas $^{6} \cdot$ Marie Etienne $^{7} \cdot$ Pepita Jean $^{8}$
}

Received: 16 June 2021 / Revised: 15 September 2021 / Accepted: 16 September 2021 / Published online: 1 October 2021

(c) W. Montague Cobb-NMA Health Institute 2021

\begin{abstract}
Haitians are the fourth largest Afro-Caribbean immigrant group in the USA, and there is a dearth of research focusing on the factors impacting their lives. As a marginalized group with extensive pre-existing conditions, Haitian immigrants are disproportionately affected by the pandemic in areas such as education, health, and economics. This paper provides a summary of existing disparities among Haitians in the USA and how COVID-19 has significantly impacted this group. It concludes with an analysis of how the Strategic Framework for Improving Racial and Ethnic Minority Health and Eliminating Racial and Ethnic Health Disparities can be used to guide, organize, and coordinate systematic planning for sustainable changes to address these disparities. Addressing immigrant and minority health in the USA requires a deeper dive into the various immigrant groups. This paper concludes with recommendations for research and policy changes necessary to eliminate disparities in the USA.
\end{abstract}

Keywords COVID-19 $\cdot$ Disparities $\cdot$ Haitian immigrant $\cdot$ Systemic change $\cdot$ Social impact

The arrival of the COVID-19 pandemic in the USA caused significant impacts in the lives of individuals at all levels while simultaneously shining a spotlight on the pre-existing disparities in many communities throughout the USA,

Judith L. Semé

jseme@westcoastuniversity.edu

1 Department of Nursing, West Coast University, 9250 NW36th Street, Doral, FL 33178, USA

2 UM School of Nursing, Schwartz Center for Nursing and Health Studies, Coral Gables, FL, USA

3 Division of Infectious Disease, Miller School of Medicine, University of Miami, Miami, FL, USA

4 Counselor Education Program, Alabama State University, Montgomery, AL, USA

5 Miller School of Medicine, University of Miami, Miami, FL, USA

6 Department of Educational \& Psychological Studies, University of Miami, Coral Gables, FL, USA

7 Benjamin Leon School of Nursing, Miami Dade College, Miami, FL, USA

8 Division of Medicine, Transplantation and Cellular Therapy, University of Miami Sylvester Cancer Center, Miami, FL, USA including many immigrant communities such as Haitians. This article provides an overview of the Haitian community, highlighting the existing disparities that existed prior to COVID-19 in the areas of education, health, and economics, to name a few, and the various ways that COVID-19 has impacted the Haitian community in these areas. The article concludes with a framework on how to address these disparities from a systemic approach.

Scholars have defined Haitians as individuals native to Haiti [1-3] and Haitian Americans as individuals born in the USA who are of Haitian ancestry. For this article, the term "Haitians" will be inclusive of individuals who were born in Haiti and in the USA who are of Haitian ancestry and identify as Haitian individuals. Since the 2020 US Census data have not yet been aggregated to reflect the current population of Haitians living in the USA, the most recent official data regarding Haitians in the USA dates to the 2010 Census. According to the US Census data, there were approximately 830,000 Haitians living in the USA ten years ago [4]. The actual number of Haitians living in the USA is generally considered to be higher, which is due to a lack of participation by Haitians in the US Census. According to the US Census [4], data collected in 2009, the geographical distribution of Haitians living in the USA is as follows: (1) 
376,000 in Florida; (2) 193,000 in New York; (3) 62,000 in New Jersey; (4) 59,000 in Massachusetts, and (5) 18,000 in Connecticut. As indicated by the census, the five states with the highest Haitian population included Florida, New York, New Jersey, Massachusetts, and Connecticut.

\section{Disparities in the Haitian Communities Before and During COVID-19}

The disparities among ethnically diverse immigrants in the USA are well-documented and span many categories. However, the most consistent areas of interest are education, health, and economics. In this section, the researchers highlight the educational, health, and economic disparities that exist in the Haitian communities prior to the pandemic of COVID-19.

\section{Educational Disparities Among Haitians}

Numerous scholarly works of literature are documenting the disproportion of COVID-19 mortality among minority populations in the US. Multiple scholars discerned that COVID19 has overwhelmingly impacted negatively African Americans/Blacks. Historically, Black students have been lagging academically compared to other ethnic groups [5, 6]. Before the pandemic, Blacks experienced an educational gap from the primary developmental stages through adulthood, with two-thirds of eighth graders lacking math and reading skills and only $25 \%$ of Blacks obtaining a bachelor's degree [7]. Moreover, the available data from state and national assessments exhibit a trend of subpar performance of Black students [8-11]. Also of interest, Blacks were among the lowest to be awarded a bachelor's degree and graduate degrees for both the 2018/2019 and 2019/2020 school year in Florida [12], as well as for the prior years [10].

The socioeconomic background of Haitian immigrant youths influenced their academic achievement before the COVID-19 pandemic [13]. Camarota [14] disclosed that $22 \%$ of Haitian immigrants over the age of 24 had not graduated high school. Statistical data reveal that $18 \%$ of Haitians 25 years of age and older have obtained a bachelor's degree [7]. By 2018, however, 79\% of Haitians 25 years of age or older received a high school degree or higher, and $19 \%$ obtained a bachelor's degree or higher [15]. Philipp [16] discovered that less than half of all Haitian adults in South Florida obtained a high school diploma, and $15 \%$ never had any formal education, resulting in the majority of Haitians working in hospitality or food service industries.

What are some of the systemic factors that contribute to such rates? A study conducted by Nicholas and Severe [17] revealed that racial segregation in Miami-Dade and Broward
County schools (as two examples) coincided with discordant academic results. High schools highly attended by Blacks and immigrant students (with two-thirds being Haitian students) had a significant decline in the Florida Comprehensive Assessment Test (FCAT) scores required for high school graduation. As a result, the graduation rates of Black students declined. More specifically, this study revealed that although Haitian students may have a good grade point average, they could not graduate due to poor FCAT scores, resulting in a certificate of completion rather than a high school degree. "Perhaps, even though African American students are attending classes, educational hegemony negatively impacts their GPA, and mathematics, science, as well as reading scores on the FCAT" [6].

Haitians regard education as an honorary insignia of paramount significance. In a study conducted by Louis [18], contributing factors to the academic success of Haitian American women at the collegiate level and beyond included "perceived self-motivation, financial assistance, accessibility to resources, self-perception, time management, spiritual life, family support, prior academic achievement, and affordability of college tuition" [18, p. 93]. Furthermore, a study [16] revealed that the academic success of school-aged children of Haitian parents attributed to the indispensable role parents enacted in equipping their children mentally, with an "emphasis on edikasyon as the foundation for enstriksyon" [16, p. 318]. The involvement of Haitian parents in their child's academic journey plays a critical role in their success.

\section{Impact of COVID-19: Education}

While COVID-19 has claimed many lives globally, it has undoubtedly made a global impact on the academic arena, especially among Haitian immigrants. The pandemic has "disproportionately impacted educational attainment in minority communities" [19] including Blacks, robbing them of a brighter future [20]. Dorn et al. [20] revealed that students of color were laggards by 3 to 5 months compared to their white counterparts, who were approximately 1 to 3 months behind during the spring term of 2020. Furthermore, [20] posit that "students of color could be six to 12 months behind, compared with four to eight months for white students.

"While all students are suffering, those who came into the pandemic with the fewest academic opportunities are on track to exit with the greatest learning loss" [20, p. 2]. The pandemic has posed a difficult challenge globally, but even more so for those already disproportionately disadvantaged. Immigrants are vulnerable to the negative impact of the abrupt adjustment of learning due to inadequate access to high-speed internet and electronic devices (such as laptops, desktops). Ryan [21] posited that 89 percent of households 
had a computer for various online purposes as of 2016 . By $2019,66 \%$ of blacks had access to broadband internet compared to $79 \%$ of their white counterparts [22]. Children of low-income households (of \$25,000 annual household income) were more inclined to have academic courses canceled (at 39\%) compared to their wealthier counterparts (with a yearly household income of $\$ 200 \mathrm{k}$ or more) at only $18 \%$ [19]. COVID-19 has incited a momentous global stoppage that has negatively impacted Blacks in the academic arena at all levels. Due to COVID-19, the remote learning format expeditiously replaced the on-ground [brick and mortar] setting. The pandemic has resulted in nearly hundreds of thousands of Florida students being out of the classroom setting in roughly a year. Screened electronic devices and increased student absenteeism supplanted formal education [23]. Dorn et al. [20] indicated that despite improvements made after the spring academic term in 2020, Blacks are among the minority groups to be more inclined to remain in the remote setting without the adequate pre-requisite of learning, despite school re-opening in Fall 2020. The multitude of students learning in a remote format is those "who need the most support, such as children for whom English is not spoken at home or is a second language ..." [23].

Although the literature is scarce, it is safe to assume that COVID-19 has further implicated the educational disparity among Haitian immigrants. Therefore, it is crucial that researchers closely analyze the negative impact COVID19 has on the academic pursuit of Haitian immigrants and resolve to alleviate these repercussions. The social determinant of education plays a crucial role in establishing academic equity that may reduce socioeconomic inequalities among Haitians in the US. The longstanding educational disparity among Haitian immigrants in the USA warrants the grassroots appeal for change and influences policymakers in formulating laws that meet this population's unique needs.

\section{Health Disparities Among Haitians}

Prior to COVID-19, intellectuals have documented the various health disparities among the Haitian community. For example, prior to the COVID-19 pandemic, non-communicable diseases such as hypertension, diabetes, and chronic kidney disease have been documented and found to be prevalent among Haitians living in Haiti [24]. Haiti has a high prevalence of cerebrovascular disease at a rate of 176 per $100,00[25,26]$. In an urban and rural region of Haiti, the prevalence of diabetes was found to be $19.7 \%$ [24]. Of note, the rate of type 2 diabetes is disproportionately high among Haitian Americans, which could be explained by cultural factors and diet [25]. Beyond diabetes, Haitians in the USA face many disparities regarding associated health issues compared to other ethnic groups. The major areas of disparity regarding infections that have been documented in research studies include viral illnesses such as Hepatitis B, HIV, and HPV. In addition, disproportions in health services regarding cervical, breast, and colorectal cancer have been noted. The reasons for these disparities are multifactorial. Important issues among Haitians include lack of knowledge, late diagnosis, and retention in care. Compared with other groups, Haitians lacked information regarding some viral illnesses and have had poorer outcomes. For example, in a group of Haitian women with HIV, it was noted that there was a lack of knowledge regarding HPV and cervical cancer [27]. A recent study regarding Hepatitis B also showed that Haitians knew less than African Americans regarding the disease [28]. With respect to HIV, there have been delays in HIV diagnosis among Haitians [29]. Haitians were also noted to have disparities in treatment responses for HIV [30, 31]. In addition, studies have shown that Haitian women are more likely to be diagnosed with late-stage breast cancer and low compliance with annual mammograms [32, 33]. Haitian-born participants were also less aware than other groups regarding the fecal occult blood tests and had not had as many colonoscopies [33-35]. These disparities have been attributed to multiple factors, including both lack of insurance and access to healthcare [21, 27]. Similarly, the researchers observed disproportions in mental health services and support for Haitians living in the USA $[1,36]$.

Research suggests that Haitians belong to several minority statuses (i.e., language, immigrant, class, race), which puts them at a greater disadvantage in the USA [12, 37]. Prior to COVID-19, there were many factors that contributed to stress in Haitian immigrants, thereby potentially yielding negative mental health outcomes. The factors include but are not limited to poverty, language barriers, racial discrimination, immigration issues, unemployment, education, interactions with the individuals in the US, and acculturation $[1,13]$. Haitians are more likely to live beneath the poverty guidelines due to these same challenges. Despite the value that Haitians place on education, the language barriers, immigration issues, and discriminatory policies can become barriers to Haitians academic success. Furthermore, [38] reports Haitians to experience harsher treatment from government officials and deal with discriminatory immigration policies than any other minority ethnic and cultural groups in the USA. [39] further supports this assertion as his research implies that $32 \%$ of Haitians were content and satisfied with their quality of life in comparison to $85 \%$ of Cubans [12]. He explains this dissatisfaction and discontentment as the result of Haitians' experience with discrimination, negative stereotypes, and employment challenges. Although there is a paucity of information regarding the mental health status of Haitians living in the US, the authors of this article are aware that Haitians deal with many challenges, thereby impacting the mental health outcomes of the Haitian community. 
However, Haitians underutilize mental health services, often due to a lack of knowledge of these services and the benefits thereof, lack of cultural competence, inappropriate and inadequate services, lack in health benefits, and a lack of trust in mental health providers, among other reasons [40].

In summary, the burden of illnesses, injury, and mortality as experienced by the Haitian immigrant has been significantly unfavorable. Haitian immigrants have succumbed to various preventable diseases due to health inequity. This paper aims to illuminate the existing health issues necessary to be resolved. It is crucial for researchers to examine the health disparities and for stakeholders in the health sector to implement strategies to close the health gap among Haitian immigrants. The authors of this manuscript are Haitian and of Haitian descent from diverse disciplines and expertise in the specific areas of psychology and mental health, nursing, medicine, and academia. They have first-hand experience with Haitian individuals and the Haitian culture through previous and ongoing research.

\section{Impact of COVID-19 on Health}

The CDC reports that Black individuals are disproportionately affected by COVID-19 [41] and overrepresented with respect to hospitalizations and deaths in the USA [41]. At the time of writing this paper, the Centers for Disease Control and Prevention (CDC) [42] reported the total number of confirmed cases of COVID-19 in the USA was 28,405,925, and the number of deaths was 511,839 [42] as of March 2, 2021. Individuals who are at highest risk of a poor prognosis from COVID-19 are those greater in age than 65 years old and those suffering from pulmonary and cardiac conditions, severe obesity, chronic kidney or liver disease, diabetes, and those with immunocompromised status and conditions (i.e., HIV, AIDS, transplants, cancers). This virus does not discriminate based on race; however, among the most impacted by this pandemic and facing challenges are African Americans in the USA [43]. Data regarding COVID19 and Haitians/Haitian Americans in the USA are limited; however, the information available suggests that they have been negatively affected. Per the Miami Herald, COVID-19 has had a major impact on Haitian Americans. The exact number of Haitian Americans impacted is unknown because state health officials do not typically track infections by ethnicity [44]. When the Miami-Dade Medical Examiners began adding "Haitian," however, at least $5 \%$ of the county's COVID-19 victims were Haitian Americans [44]. At present, the prevalence of COVID-19 in the Haitian population is unknown as Haitians are often subsumed into the African American population.

There remains a paucity of research pertaining to the impact of COVID-19 due to the novel nature of the virus.
Hence, data specifically related to the impact of COVID19 on mental health outcomes in the Haitian population in the USA are scarce. However, an important aspect of Haitian culture involves social connectedness and interactions. The Haitian culture relies heavily on family support and community to thrive. Haitians are more likely to have been closely connected with family members that are immediate and extended, as well as friends [17]. Family is a source of support for Haitians, and that support can be in the form of financial, childcare, immigration process, housing, emotional, and others. To help decrease the spread of COVID19 , one of the CDC guidelines includes social distancing and a reduction of large gatherings. However, an important characteristic of the Haitian culture is being tangibly present and surrounded by family [17]. This has impacted the Haitian community tremendously and has the potential to negatively impact the mental health of Haitians. Additionally, the Haitian church and spiritual leaders have always been a support to the Haitian community and aided with mental health support. Due to COVID-19 and CDC guidelines, many churches transitioned to provide live streaming services. However, many Haitian churches don't have the technological infrastructure in place to stay connected to their members via live streaming. Furthermore, the older generation Haitians also lacked the technological resources to connect. This lack of spiritual connection and support has the potential to impact the mental health outcomes of Haitians in the US.

Overall, as a population that frequently experiences challenges with assimilation, race-based trauma, poverty, undereducation, and health disparities, it is safe to assume that there will be negative impacts to the Haitian population living in the USA because of COVID-19. It is imperative that researchers examine these impacts and implement changes to mitigate some of the negative ramifications.

\section{Economic Disparities Among Haitians}

It is well documented that economic disparities among various ethnic groups, specifically Haitians, are widening. In fact, the COVID-19 pandemic has posed severe economic impediments to many while causing indirect threats to the security of millions across the globe [45]. For example, unemployment rates have skyrocketed resulting in 6.6 million unemployment insurance claims in late March 2020 in the USA alone [45]. Additionally, food shortages and insecurity has disproportionately threatened the nutritional well-being across racial and ethnic subgroups [45]. Although the 2020 data are not yet available regarding the economic standing of Haitians living in the US, it is safe to assert that loss of employment has skyrocketed. Forty percent of the Haitian diaspora residing in the USA are 
employed in service occupations [18]. Unfortunately, due to COVID-19's social distancing guidelines, service-related industries ceased their work operations leaving many unemployed [45]. While nearly all Haitian immigrants who obtain lawful legal residence become US citizens and participate in the labor force via employment in service occupations, they are recorded to have lower household income [15]. What differentiates groups of individuals living in any society is their level of income and wealth. Understanding both concepts can provide deeper insights into the existing gaps across ethnicities. Economic disparity is the unequal distribution of income and wealth between groups of people living within societies. Such inequalities exist not only in the USA but in other parts of the world as well and affect a vast number of men and women. To clearly understand the scope of inequalities, one must examine differences in income and wealth. Income refers to money received by a person or household over an extended period (e.g., wages, salary, government assistance, etc.), while wealth focuses on one's total sum of assets (e.g., financial holdings, savings, home, etc.). It is safe to conclude that the major difference between both economic indicators is that wealth generates income. Therefore, economic disparities are dependent upon the acquisition of wealth. According to [46], Blacks are found in the lowest ranks in terms of interest-earning assets.

One of the greatest barriers to financial security is the lack of accumulated wealth. Living paycheck to paycheck creates greater struggles and hardships for families \& households. The latter becomes compounded with the addition of children within the household. Gender and race are additional components that affect one's overall income. Although there has been a slight increase in median income from 2018 to 2019, there still exists a great gap between Black householders and the rest of the population. According to [47], Black householders had a median income of $\$ 42,110$ in 2018 and $\$ 45,438$ in 2019. In contrast, other races have a median income of $\$ 23,000$ more than their White and Asian counterparts [47]. Furthermore, male householders have a median income of $\$ 13,884$ more than the female households. These data, however, do not take into effect the ethnicities of the householders. Although 70\% of Haiti's skilled workers do not live in Haiti and reside elsewhere, their income drives $29 \%$ of Haiti's GDP, $25 \%$ of Haiti's overall state budget contributes to an overall $\$ 2.4$ billion worth of income, $\$ 1.4$ billion of which comes from the USA [48]. Financial security also seems to correlate with the age of the householder. There seems to be a moderate increase in median income between the ages of 25-54. The income slowly decreases after the age of 54. One can then infer that financial security may become gloomy for those in the latter age group. Employers are less likely to hire someone in their fifties.

The US Census Bureau [47] reports that over $20 \%$ of Black males are in construction type jobs, whereas Black females comprise approximately $34.2 \%$ of the educational \& health services sector. Although more women are employed in the workforce, they are unequivocally being paid less than men. There is an insurmountable number of jobs that Haitians hold in the US. For example, they hold positions in politics, science, accounting, finance, and law enforcement. However, occupations in which Haitian immigrants heavily gravitate towards include health care and education fields. As a matter of fact, $36 \%$ of healthcare and education-related positions are filled by Haitians, whereas service occupations are heavily filled by $40 \%$ of Haitians in the diaspora [49]. Furthermore, Haitians that are non-US Citizens are paid over $\$ 23 \mathrm{~K}$ less than naturalized citizens [47, 49]. This harsh reality has been compounded post the COVID-19 pandemic and truly experienced within Haitian households.

In sum, Haitians not only have experienced and continuously experience intense financial hardships in Haiti but in the USA as well. There is a clear disparity between the wealthy and the employed. Such a financial gap is further extended when factoring in gender, age, and immigration status. Financial security in the USA for Haitians is not unattainable despite crises such as the COVID-19 pandemic; however, policies need to be in place to eradicate the systemic financial inequalities inherent within the employment sector.

\section{Impact of COVID-19 on Economy}

It is no secret that job loss has been a major byproduct of COVID-19 in the USA. With school and factory closures and the decreased bus and public transportation capacity, many Haitian businesses have greatly suffered. Haiti's precautionary measures contributed to low levels of COVID19; however, job loss and food insecurity are directly linked to the virus. Unlike the USA, Haiti's government had no plan of action and limited resources to support individuals who were no longer able to work. As mentioned above, Haiti has suffered economically for years; in 2020, political unrest and COVID-19 only exacerbated these problems. Economists predict that continued unrest in response to the country's food insecurity and job loss may worsen in early 2021. This prediction is (c) estimated at an astounding 3.4\% GDP decrease [48].

Job loss in the USA during the pandemic has contributed not only to emotional trauma but to financial insecurities as well. Although there is minimal research on the actual number of Haitians impacted financially by COVID-19, African Americans are disproportionately affected by job loss or unemployment. Additionally, stigmatization of African American people affected with COVID-19 impedes access to the level of care one receives. Hospitals treating patients with COVID-19 have been physically attacked. Health care 
workers have been threatened, and Ministère de la Santé Publique et de la Population (MSPP) mobile-testing teams stoned. Organizations such as Groupe Haïtien d'Étude du Sarcome de Kaposi et des Infections Opportunistes (GHESKIO) are engaging community leaders to overcome this mistrust and stigma within those living in the USA and on the island [50].

In short, additional research needs to be conducted within the area of economics for Haitians and Haitian Americans. Moreover, it is safe to conclude that such economic disparities can greatly impact the overall well-being of Haitian families, specifically without a steady source of income due to unemployment. The inability to work due to COVID-19 has greatly widened the gap between the employed and those now facing poverty. As such, systemic policies need to be in place to address and eradicate the economic disparities that exist among the employed and the wealthy.

\section{Addressing COVID-19 Impact for Haitians: Systemic Change}

This paper highlights and the various disparities existing in the Haitian community. Identifying these disparities is not enough and in this section the authors offer a model that can be used to address these disparities for Haitians in the US. Addressing disparities, especially among ethnically diverse and immigrants has occurred at the individual level and while such interventions are necessary, addressing disparities requires systemic and transformative changes. Many models address systemic changes, but an effective model that targets all the key aspects and focuses on strategic and sustainable changes is the issue highlighted in this paper, which calls for a more systematic intervention for sustainable changes. The Strategic Framework for Improving Racial and Ethnic Minority Health and Eliminating Racial and Ethnic Health Disparities (Framework) [33] presented here is intended to help guide, organize, and coordinate the systematic planning, implementation, and evaluation of efforts needed within the Haitian communities to achieve better results relative to disparities reductions. The Framework reflects current knowledge and understanding of the nature and extent of disparities, their causes or contributing factors, effective solutions, and desired outcomes and impacts. It reinforces the importance of having and using science and knowledge as the basis for planning and implementing our program-, research-, or policy-oriented actions and activities. The Framework also suggests the need to adequately evaluate the efforts so that new knowledge can be used for continuous improvement. The Framework consists of five areas, sequentially organized into different components and the steps needed to develop and implement each. Figure 1 depicts the five interconnected levels: (a) Long-term Problems, (b) Contributing Factors, Strategies and Practices, (d) Outcomes and Impacts, and (f) Long-Term Objectives and Goals.

Step 1: Understanding the Long-Term Problems At the start of the model, the long-term level addresses the need for dissecting the issues of focus (such as health, education, economic) and aligning the systemic issues (such as lack of systems approach, inadequate resources.) that perpetuate or maintain the issue. Understanding the different categories of the problem is the groundwork needed. For example, in the case of health disparities, it is important to understand the health status of Haitians and health care managing the burden associated with higher morbidity and mortality. Complementary to that is an examination of system issues such as adequate resources, support planning and evaluation, and willingness of the stakeholders to work collaboratively to address the issues.

Step 2: Examining the Contributing Factors Given the complexity of the problem and the array of factors that contribute to the disparities in Haitian communities. The Framework calls for an examination of these factors in three main categories: (a) Individual-level factors, (b) Environmental-/community-level factors, and (c) System-level factors. At an individual level, there is a need to understand the knowledge and attitudes, skills, and behaviors that individuals have in our communities about the issues. With regards to the environmental and community level, factors such as the physical environments (i.e., natural disasters, crimes/ violence), social/cultural characteristics (such as bias and

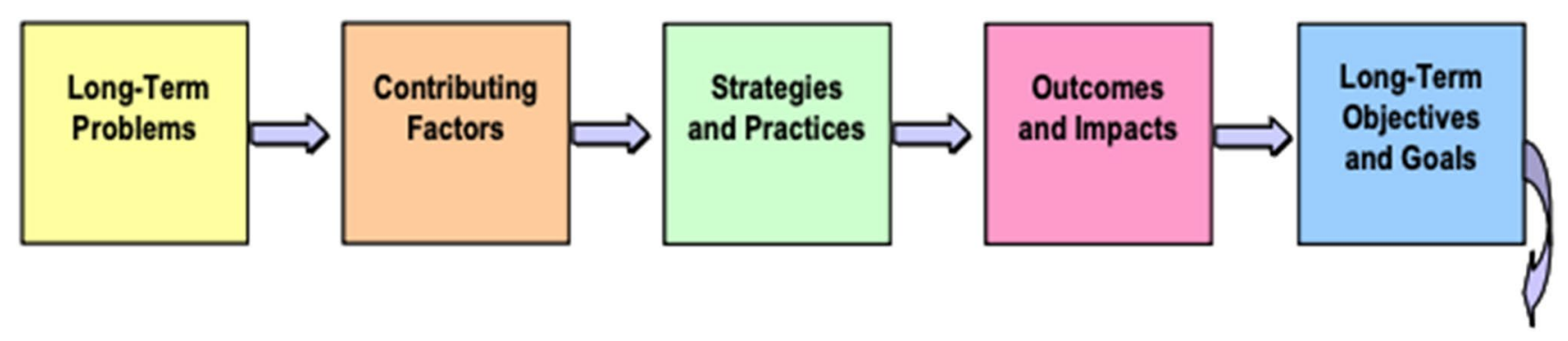

Fig. 1 General structure of the strategic framework 
discriminations), and economic, political, and organizational. At the systems level, there is a need to examine the assets, resources, leadership in the community, information access, and dissemination. Collectively, at this system level, there is a need to ensure that the products and services being created and implemented in the communities are reflective of the needs of the people for whom these programs are being created.

Step3: Supporting Effective Strategies and Practices In addressing some of the issues existing in the communities, it is crucial that the strategies and practices that are being implemented are based on evidence and research supporting such strategies. In addition, having strategies and practices that can impact the various levels discussed above should be the focus while picking strategies that only target one area neglecting the others. However, this should not be at the expense of evaluating indigenous practices requiring further studies by the scientific fields. Thus, a more comprehensive approach is needed to effectively address systemic issues occurring in many minoritized communities in the US.

Step 4: Outcomes and Impacts Today, most of the strategies and interventions being implemented to address disparities in most communities rarely include measurable evaluation methods. This step highlights that subsequently, to implementing specific strategies and practices in step, specific, measurable outcomes and impacts must be developed and applied. Such a process should call for the integration of short-term (outcomes) and long-term (impacts) measures. These strategies must be grounded in research and expert observations. More efforts must be made in documenting the results of the systemic interventions being implemented and the overall impact of these interventions in the communities of interest. Ultimately, this step demands that specific outcomes and impacts must be integrated with all intervention programs to produce the research necessary to document what works for whom and under what circumstances.

Step 5: Long-term Objectives and Goals The last step of the Framework focuses on looking to the future. It calls for "states, communities, and other stakeholders can use this framework to guide the selection of problems, factors, and strategies/practices that can be linked to short-term, intermediate-, and long-term objectives and goals, based on identified outcomes and impacts" [47]. These goals and objectives goals must be grounded within the three levels of individuals, community, and systems.

\section{Conclusion and Recommendations}

In summary, this Framework highlights the need and role that systems-level factors play in promoting and inhibiting the elimination of the disparities discussed in this paper. The Framework presented here is a vision for what can and should be done in the Haitian communities for sustainable change. A systems approach is needed in the community that may reinforce the Haitian motto of L'union fait la force [ strength in unity], implying that all sectors are engaged in unity around an issue of education, health, or economic. As such, each party considers the causal or contributing factors and problems it is most likely to be able to impact with its particular strengths and talents. Resources and assets can then be coordinated and leveraged in more systematic and strategic ways to achieve a range of outcomes and impacts needed so that, together, all parties can more effectively and efficiently contribute to and achieve long-term objectives and goals. This focus on systems applies as well to how various fields of research work together for greater effectiveness and efficiency to address weaknesses and gaps in scientific knowledge. A systems approach to working across diverse research disciplines may be better able to illuminate our understanding about the nature and extent of minority health and health disparities problems, especially for small population groups, the relative importance of and interrelationships between causal or contributing factors, more effective ways to break the causal chain that produces greater burdens of preventable disease and premature death among racial and ethnic minorities and the means for measuring desired outcomes and assessing progress. The authors of this paper believe that the structure and approach outlined in the Framework offers a rational and systematic, yet broad and flexible, way of viewing and informing our efforts to achieve a thriving Haitian community.

The focus of this paper aims to deliver recommendations for systemic and sustainable changes concerning the increasing number of Haitians in the US, with the majority residing in the Southern and Northern regions. This migration has resulted in persistent disparities from education to health to economic among this population. It is important to note the colossal educational gap that exists across all socioeconomic statuses. There is a high rate of chronic conditions and other health issues that have prevailed prior to COVID-19, thus increasing the mortality and morbidity from COVID-19. Furthermore, inadequate medical and mental health professionals of Haitian descent are concerning in addition to the economic disparities among the poor and the wealthy.

To effectively address these distressing concerns of the general health of this group, the contributors of this article have the following recommendations: (a) educate Haitian immigrants regarding CDC guidelines to prevent COVID19. (b) establish mobile health systems for access to health services (c) form community partnerships to promote awareness. More specifically, mental health concerns of this population may best be addressed by effectively training community leaders with mental health first aid to assessing the impact of COVID-19 on mental health. This article also suggests developing a referral system for leaders to refer to 
Haitian mental health therapists. Moreover, acquiring mobile health clinics to increase access to mental health services may prove beneficial. As it concerns the economic disparities, the authors of this paper suggest the encouragement of less dependency on the US government. It may be necessary for stakeholders to assist Haitian immigrants with employment applications, as necessary. There is a dire need to address the overwhelming disparities that exist among Haitians.

Funding All authors declare they did not receive any funding to assist in the preparation of this manuscript. The authors declare they have no financial nor proprietary interest in any material discussed in this manuscript.

\section{Declarations}

Conflict of interest The authors have no conflict of interest to declare that are relevant to the content of this article.

\section{References}

1. Barnett J. Examining the lived experiences of acculturation among Haitian immigrants living in the United States: An Interpretative Phenomenological Analysis. [Doctoral dissertation, Auburn University.] Proquest Dissertation Publishing. 2018.

2. Bivins B. The lived experience of Haitian American women with type 2 diabetes mellitus. [Doctoral dissertation, Barry University.] Proquest Dissertation and Thesis Global. 2018.

3. Giger JN, Haddad L. Transcultural nursing: assessment and intervention. 8th ed. St. Louis: Elsevier; 2021.

4. US Census Bureau. The Foreign-Born Population in the United States: 2010. American Community Briefs. 2012. https://www. census.gov/prod/2012pubs/acs-19.pdf.

5. Miranda A, Webb L, Brigman G, Peluso P. Student success skills: a promising program to close the academic achievement gap for African American and Latino students. Prof Sch Couns. 2007;10(5):490-7. https://doi.org/10.5330/prsc.10.5.rx6g3g7141 w2310q.

6. Reid Marks LM, West-Olantuji C, Goodman RD. A pilot study evaluating the Parent Proficiencies Questionnaire for African American Parents (PPQ-AA). Urban Educ Res Policy. 2016;4(1):99-109.

7. US Census Bureau. The Population with Haitian Ancestry in the United States: 2009. American Community Briefs. 2010. https:// www.census.gov/prod/2010pubs/acsbr09-18.pdf.

8. Educational Testing Services [ETS]. A snapshot of individuals who took the GRE general test. 2018. https://www.ets.org/s/gre/ pdf/snapshot_test_taker_data_2018.pdf.

9. Florida Department of Education [FDOE]. 2020 end-of-course assessments. 2020. http://www.fldoe.org/accountability/asses sments/k-12-student-assessment/results/2020.stml.

10. National Center for Education Statistics [NCES]. Table 226.10. Number, percentage distribution, and SAT mean scores of high school seniors taking the SAT, by sex, race/ethnicity, first language learned, and highest level of parental education: 2017, 2018, and 2019. 2019. https://nces.ed.gov/programs/digest/d19/ tables/dt19_226.10.asp.
11. National Student Clearinghouse Research Center. Completing college national and state reports. 2020. https://nscresearchcent er.org/wp-content/uploads/Completions_Report_2020.pdf.

12. State University System. Degrees awarded by student demographic. 2020. https://flbog.ondemand.sas.com/SASVisualA nalytics/?reportUri=\%2Freports\%2Freports\%2F2243f686-95da424d-afd2-08d12d5c924d\&page=vi6\&sso_guest=true.

13. Nicolas G, Desilva A, Prater K, Bronkoski E. Empathic family stress as a sign of family connectedness in haitian immigrants. Fam Process. 2009;48(1):135-50.

14. Camarota SA. Fact sheet on Haitian immigrants in the United States. Center for Immigration Studies. 2010. http://cis.org/ HaitianImmigrantFactSheet.

15. Nicolas G, DeSilva A, Rabenstein K. Educational attainment of Haitian immigrants. Urban Educ. 2009;44(6):664.

16. Phillipi DO. Haitian adult immigrants as learners and parents. 2016. https://scholarworks.waldenu.edu/cgi/viewcontent.cgi? article $=3965 \&$ context $=$ dissertations.

17. Nicholas T, Severe L. School segregation, educational disparities, and impacts on Haitian youth in South Florida. In: Plakhotnik MS, Nielsen SM, editors. Proceedings of the Seventh Annual College of Education Research Conference: Urban and International Education Section. Florida International University, Miami. 2008. pp 98-104. http://coeweb.fiu.edu/research_ conference/.

18. Louis M. Factors That Contribute to the Educational Success of Haitian-American Women. [Doctoral dissertation, Andrews University]. Digital Commons Publishing. 2009. https://digitalcom mons.andrews.edu/dissertations $/ 530$.

19. USA Facts. How the economy, Covid-19, and standard of living, differs for Blacks and Hispanic Americans. Retrieved from How the economy, COVID-19, and standard of living differs for Black and Hispanic Americans (usafacts.org). 2021.

20. Dorn E, Hancock B, Sarakatsannis J, Viruleg E. Mind the gap: COVID-19 is widening racial disparities in learning, so students need help and a chance to catch up McKinsey. 2020. https://www. mckinsey.com/ /media/McKinsey/Industries/Public\%20and\% 20Social\%20Sector/Our\%20Insights/COVID\%2019\%20and\% 20learning $\% 201$ loss $\% 20$ disparities $\% 20$ grow $\% 20$ and $\% 20$ students $\%$ 20need $\% 20 \mathrm{help} / \mathrm{COVID}-19$-and-learning-loss-disparities-growand-students-need-help-v3.pdf?shouldIndex $=$ false.

21. Ryan C. Computer and internet use in the United States: 2016. The United States Census Bureau. Retrieved from Computer and Internet Use in the United States: 2016 (census.gov). 2018.

22. Pew Research Center. Internet broadband fact sheet. Retrieved from Demographics of Internet and Home Broadband Usage in the United States I Pew Research Center. 2019.

23. Hudson T, Ross M. Television special. Class of COVID-19: an education crisis for Florida's vulnerable students (full report) [Online Video]. 2021. https://classofcovid.org/watch-televisionspecial. Accessed: June 192021.

24. DeGennaro V Jr, Malcolm S, Crompton L, Vaddiparti K, et al. Community-based diagnosis of non-communicable diseases and their risk factors in rural and urban Haiti: a cross-sectional prevalence study. BMJ Open. 2018;8(4):e020317. https://doi.org/10. 1136/bmjopen-2017-020317.

25. Bivins B, Hershorin I, Umadhay L. Understanding type 2 diabetes mellitus among Haitian American women: a cultural perspective. J Natl Black Nurs Assoc. 2020;31(1):32-40.

26. Seme J. Rural Haiti residents living with cerebrovascular diseaserelated disabilities: a phenomenological inquiry. [Doctoral dissertation, Barry University.] Proquest Dissertation and Thesis Global. 2018.

27. Kenya S, Carrasquillo O, Fatil M, Jones J, Jean C, Huff I, Kobetz E. Human papilloma virus and cervical cancer education needs among HIV-positive Haitian women in Miami. Womens Health 
Issues. 2015;25(3):262-6. https://doi.org/10.1016/j.whi.2014.12. 007.

28. Jones P, Soler J, Solle NS, Martin P, Kobetz E. A mixed-methods approach to understanding perceptions of hepatitis B and hepatocellular carcinoma among ethnically diverse Black communities in South Florida. Cancer Causes Control CCC. 2020;31(12):107991. https://doi.org/10.1007/s10552-020-01345-6.

29. Cyrus E, Sheehan DM, Fennie K, Sanchez M, Dawson CT, Cameron M, Maddox L, Jo Trepka M. Delayed diagnosis of HIV among non-Latino Black Caribbean immigrants in Florida 2000-2014. J Health Care Poor Underserv. 2018;29(1):266-83. https://doi.org/10.1353/hpu.2018.0019.

30. Colasanti J, Nguyen L, Kiem JT, Deeb K, Jayaweera D. Disparities in HIV-treatment responses between Haitians, African Americans, and Hispanics living in Miami-Dade County, Florida. J Health Care Poor Underserv. 2012;23(1):179-90. https://doi.org/10.1353/ hpu.2012.0004.

31. Cyrus E, Dawson C, Fennie KP, Sheehan DM, Mauck DE, Sanchez M, Maddox LM, Trepka MJ. Disparity in retention in care and viral suppression for black Caribbean-born immigrants living with HIV in Florida. Int J Environ Res Public Health. 2017;14(3):285. https://doi.org/10.3390/ijerph14030285.

32. Kobetz E, Mendoza AD, Barton B, Menard J, Allen G, Pierre L, Diem J, McCoy V, McCoy C. Mammography use among Haitian women in Miami, Florida: an opportunity for intervention. J Immigr Minor Health. 2010;12(3):418-21. https://doi.org/10. 1007/s10903-008-9193-8.

33. U.S. Department of Health and Human Services, Office of Public Health and Science, Office of Minority Health. A Strategic Framework for Improving Racial/Ethnic Minority Health and Eliminating Racial/Ethnic Health Disparities. Rockville, MD: Office of Minority Health. 2008. https://minorityhealth.hhs.gov/Assets/ PDF/Checked/OMH\%20Framework\%20Final_508Compliant. pdf. Accessed 12 May 2021.

34. Gwede CK, William CM, Thomas KB, Tarver WL, Quinn GP, Vadaparampil ST, Kim J, Lee JH, Meade CD. Exploring disparities and variability in perceptions and self-reported colorectal cancer screening among three ethnic subgroups of U. S. Blacks. Oncol Nurs Forum. 2010;37(5):581-91. https://doi.org/10.1188/ 10.ONF.581-591.

35. Wilcox ML, Acuna JM, de la Vega PR, Castro G, Madhivanan P. Factors affecting compliance with colorectal cancer screening among households residing in the largely Haitian community of Little Haiti, Miami-Dade County, Florida: an observational study. Medicine. 2015;94(18):e806.

36. Brutus A. The Effects of Ethnic Identity and Acculturation on the Mental Health Service Utilization of Haitians. Order No. 3340538 Pace University. Ann Arbor: ProQuest. 2008.

37. Belizaire LS, Fuertes JN. Attachment, coping, acculturative stress, and quality of life among Haitian immigrants. J Counsel Dev. 2011;89:89-97.
38. Pierre-Louis F Jr. Haitians in New York City: transnationalism and hometown associations. Gainesville: University Press of Florida; 2006.

39. Stepick A. Pride against prejudice: Haitians in the United States. Boston: Allyn \& Bacon; 1998.

40. Desrosiers A, Fleurose SS. Treating Haitian patients: key cultural aspects. Am J Psychother. 2002;56(4):508-21.

41. Moore JT, Ricaldi JN, Rose CE, Fuld J, Parise M, Kang GJ, Honein MA. Disparities in incidence of COVID-19 among underrepresented racial/ethnic groups in counties identified as hotspots during June 5-18, 2020-22 states, February-June 2020. Morb Mortal Wkly Rep. 2020;69(33):1122.

42. Centers for Disease Control and Prevention. COVID data tracker. 2020. https://covid.cdc.gov/covid-data-tracker/\#casestotalcases

43. Laurencin CT, McClinton A. The COVID-19 pandemic: a call to action to identify and address racial and ethnic disparities. J Racial Ethn Health Dispar. 2020;7(3):398-402. https://doi.org/10.1007/ s40615-020-00756-0.

44. Charles J, Ovalle D. COVID-19, a stigma to many, quietly taking a toll on South Florida's Haitian community. Miami Herald. Coronavirus takes a heavy toll on Haitians in South Florida I Miami Herald . 2020.

45. Fitzpatrick KM, Harris C, Drawve G, Willis DE. Assessing food insecurity among US adults during the COVID-19 pandemic. J Hunger Environ Nutr. 2021;16(1):1-18. https://doi.org/10.1080/ 19320248.2020.1830221.

46. US Census Bureau. Ownership Rates for Assets at Financial Institutions and Other Interest Earning Assets. Retrieved from Wealth, Asset Ownership, \& Debt of Households Detailed Tables: 2017 (census.gov). 2017.

47. US Census Bureau. Current Population Survey Tables for Household Income. Retrieved from Household Income: HINC-02 (census.gov). 2020.

48. The World Bank. Predicting Food Crises 2020. The World Bank. Afghanistan, Burkina Faso, Ethiopia, Guatemala, Haiti, Kenya, Mali, Mozambique, Mauritania, Malawi, Niger, Nigeria, Sudan, Somalia, South Sudan, Predicting Food Crises 2020, Dataset for reproducing working paper results (worldbank.org). 2020.

49. Migration Policy Institute. Haitian immigrants in the United States. https://www.migrationpolicy.org/article/haitian-immig rants-united-states-2018 . (2020, August 12).

50. Rouzier V, Liautaud B, Deschamps M. Facing the monster in Haiti. N Engl J Med. 2020;383(1):1-2. https://doi.org/10.1056/ NEJMc2021362.

Publisher's Note Springer Nature remains neutral with regard to jurisdictional claims in published maps and institutional affiliations. 